\title{
MULTISCALE INTERACTIVE COMMUNICATION: INSIDE AND OUTSIDE THE THUN CASTLE
}

\author{
Giovanna A. Massari ${ }^{\mathrm{a}^{*}}$, Fabio Luce ${ }^{\mathrm{b}}$, Cristina Pellegatta ${ }^{\mathrm{a}}$ \\ ${ }^{\text {a }}$ Engineering Faculty, University of Trento, Via Mesiano, 77 - 38123 Trento, Italia \\ tel. +39046128.2644 / 2615, fax +390461282672 \\ giovanna.massari@unitn.it, cristina.pellegatta@unitn.it \\ ${ }^{\text {b }}$ University “Sapienza” of Rome, Piazza Borghese, 9 - 00186 Roma, Italia - fabio.luce@fastwebnet.it
}

KEY WORDS: Cultural Heritage, Databases, Hypertext, Landscape, Modelling, Virtual museum.

\begin{abstract}
:
The applications of informatics to architecture have become, for professionals, a great tool for managing analytical phases and project activities but also, for the general public, new ways of communication that may relate directly present, past and future facts. Museums in historic buildings, their installations and the recent experiences of eco-museums located throughout the territory provide a privileged experimentation field for technical and digital representation. On the one hand, the safeguarding and the functional adaptation of buildings use 3D computer graphics models that are real spatially related databases: in them are ordered, viewed and interpreted the results of archival, artistic-historical, diagnostic, technological-structural studies and the assumption and feasibility of interventions. On the other hand, the disclosure of things and knowledge linked to collective memory relies on interactive maps and hypertext systems that provide access to authentic virtual museums; a sort of multimedia extension of the exhibition hall is produced to an architectural scale, but at landscape scale the result is an instrument of cultural development so far unpublished: works that are separated in direct perception find in a zenith view of the map a synthetic relation, related both to spatial parameters and temporal interpretations.
\end{abstract}

\section{RÉSUMÉ:}

Les applications de la science informatique à l'architecture sont désormais, pour les spécialistes, des instruments irremplaçables pour gérer en même temps les parties liées à l'analyse et celles du projet; elles sont cependant, pour le grand public, de nouveaux moyens de communication qui peuvent établir des relations directes entre ce qui se passe en ce moment et ce qui vient de se passer ou qui va bientôt se passer. Pour les techniques de la représentation numérique, les nouveaux musées réalisés à l’intérieur des bâtiments historiques, les expositions et les toutes récentes expériences des “éco-musées”, sont des champs d’expérimentation privilégiés. Pour la conservation et le changement de fonction des bâtiments, on utilise des modèles "infographiques" 3D, qui sont de vraies sources des données rapportées à l'espace, où peuvent être ordonnées, consultées et interprétées les recherches d'archives, historiques, artistiques, diagnostiques, technologiques, constructives, mais aussi les hypothèses sur la faisabilité du projet. En même temps, la transmission des données et des éléments liés à la mémoire collective, repose sur des plans interactifs et des systèmes hypertextuels qui donnent accès à de vrais musées virtuels. A l'échelle de l'architecture, on obtient ainsi une espèce d'agrandissement multimédia de la salle d'exposition, tandis qu'à l'échelle du paysage on a un instrument de valorisation culturelle jusqu'ici inédit: des objets, autrefois séparés dans la perception directe, ont maintenant, à travers le regard zénithal du plan, la possibilité d'une description synthétique de leurs relations dans l'espace et dans le temps.

\section{INTRODUCTION}

The tools of digital representation have profoundly changed the ways of knowledge of historical architecture and have become, for professionals, an invaluable system to correlate the project activities' analytical phases. The major difficulty in the management of acquired data and the simulation of the subsequent choices of action lies, perhaps, in the identification of applications commercially useful to the needs and timing of the project might it be oriented to the conservation, reuse or general fruition.

The applications of informatics to architecture also enhance the means of public communication and effectively combine their own products to the images offered by traditional photographic film techniques. Virtual 3D static and dynamic reconstructions, have three main values: the chance to see the spaces under unusual and not directly perceptible in the reality points of view; the ability to rebuild and a past view that is no more or could have been; the opportunity to anticipate a future that may be or the possible alternatives to the not yet realized project. Not only: interactive multimedia communication means associate representations' evocative power the explicative one of words.

One of the most open to experimentation areas of application consists in museum exhibit locations, the objectives of which concern both the functional preservation and adaptation of buildings and the upgrade of the forms and content transmission, and so the expansion of reachable user typologies: this applies to different scales of intervention, including the possibility of a museum functions of the landscape. These

\footnotetext{
Corresponding author.
} 
considerations are the basis of a research work in progress on one of the most famous monuments in Trentino and its territory; from the architectural survey covering some parts of the Thun castle, the interest has extended to the construction of a $3 \mathrm{D}$ model that could be both comprehensive support for the development of restoration and as a means of communication between architecture and the places with which it interacts. In the scalar step, from object to context, the virtual model becomes one of the main components of digital interactive extended to the territorial map; the map, both as mapping and hypertext interface, enables a dialogue between archival, iconographic, bibliographic documents and the quantity of data supplied by the array of historical-geographical, socio-economic and aesthetic-naturalistic regional studies.

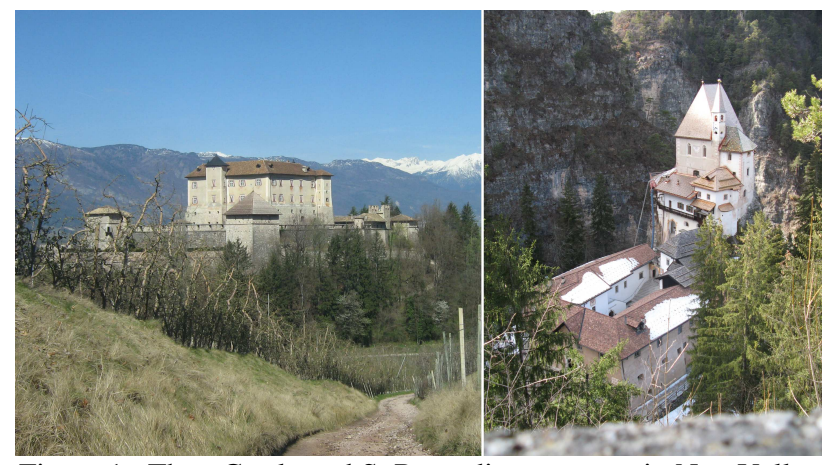

Figure 1. Thun Castle and S. Romedio sanctuary in Non Valley

\section{ARCHITECTONIC MODELS AND DATA BANKS: THE STUDY-CASE}

The Thun Castle is one of the most prestigious architectural complexes in the Trentino region; its history, linked to the evolution of the noble house of the Counts of Thun and closely related to the events of the Bishop Principate of Trento, also concerns the European Habsburg Empire thanks to the ties of kinship and family and shines today in the important historical and artistic heritage of the castle, to whom a strong capacity for tourist attraction and reverb on the cultural texture of the valley is owed. At first glance the Non Valley shows the passenger the richness and fertility also attested in archival documents and in accordance with which, in the past, the valley was protected with special status and privileges by the bishops of Trento. The valley opens to the west of the Adige Valley, near the confluence of the Noce in the Adige river: the most important town is Cles, which stands at the side of the great artificial lake of Santa Giustina; the mountains slopes are covered with forests and pastures, hills and valleys are fully planted with fruit and arable land, the landscape is dotted with historical constructions, crisscrossed by trails and dotted with ancient environmental goods. The history dates back to Roman settlements, but the period of greatest architectural development is in the Middle Ages when the Thun Castle, Bragher Castle, Coredo Castel, Cles Castel but also the sanctuary of San Romedio or the Assessor buildings of Cles and Coredo, which were the most important legal-administrative centers of the period, were built.

The restoration of the Thun Castle begun in the first mid-90s, with the ownership transferral to the Autonomous Province of Trento; the Superintendence for Architectural Heritage makes a preliminary planimetric survey campaign showing all the complex with the dual aim of launching the recovery project's
Palace, now completed, and to consolidate the city walls and ramparts, and to allow the opening of the external parts to visitors.

In 2008, the Superintendents entrusts to the University of Trento the task of producing geometric surveys and thematic representations of parts of the walls and towers to the north of the building in order to acquire the knowledge necessary to the project progress; the complex fortified system surrounding the building dates back to the sixteenth century and is made up of towers, walls, battlements, ramparts and a moat: an arcade divided by ten columns of stone and wooden trusses, intended for defence of the northern access and was used protect cannons from the weather. The research group investigates the previously executed topographic and photogrammetric surveying, develops a 3D geometric and figurative model that includes photo-plans of all external surfaces, performs detailed survey of the trusses and columns of the porch for the purpose of structural consolidation. The topographic polygonal lines made the identification of all the points necessary to define the building volumes, the section plans, the walls' position and the collocation of the vaults, and the unification of the various measure stages possible; the procedures of plane photogrammetry, applied to available prospects, have provided useful digital photo-plans for the figurative completion of the geometric model but also for the design of wall textures and of the construction tracks, the deterioration and signs of alteration "mapping", the stratigraphy reading; finally, traditional longimetric survey has allowed the detailed analysis of external openings and interior finishing elements and decorations. All the data acquired in the survey campaigns converges in the construction of a single digital 3D digital elaboration, from which representations of plants and prospects in scale 1:50 and 1:20 can be exported. The model is designed in graphic-numeric "worksheets", the name of which makes the content instantly recognizable: each layer corresponds to a homogeneous set of graphic entities organized in a consistent and functional manner both for the identification of the parts as for the production of drawings to different scales.

The 3D info-graphic model has the indispensable role of cornerstone structure of the learning and design process and is configured as a "geometry frame" capable of meeting different needs: first of all, to document with high reliability, metric and spatial dimensions and materials of the building during the survey; then, to archive the results of diagnostic tests, in situ or in laboratory, designed to integrate the archival data with artistic-historical and technological-structural data; then to assess the feasibility of the intervention and make verifiable the prevision of the reuse and the technological adaptation project; and, lastly, to describe the historical-morphological evolution of the castle and simulate its ideal reconstruction through the disappeared construction phases or the predicted but not realized interventions, which often are only clues etched on the surfaces of the building or marked by abnormal measures of the elements. The management tools of alphanumeric information and their association to vector and raster elements allow converting the CAD model in a real archive of spatially related information, viewable through easily implementable in time tabs; the experimentally developed database is based on the organization and preparation in appropriate digital formats of all the available information, and is fully anchored to the geometric model and is aimed at cataloging, consultation and interpretation of all results at various analytical and design stages; the digital representation confirms its role before as a conceptual rather than material tool, the only one able to control the project of systematic knowledge of the castle. 


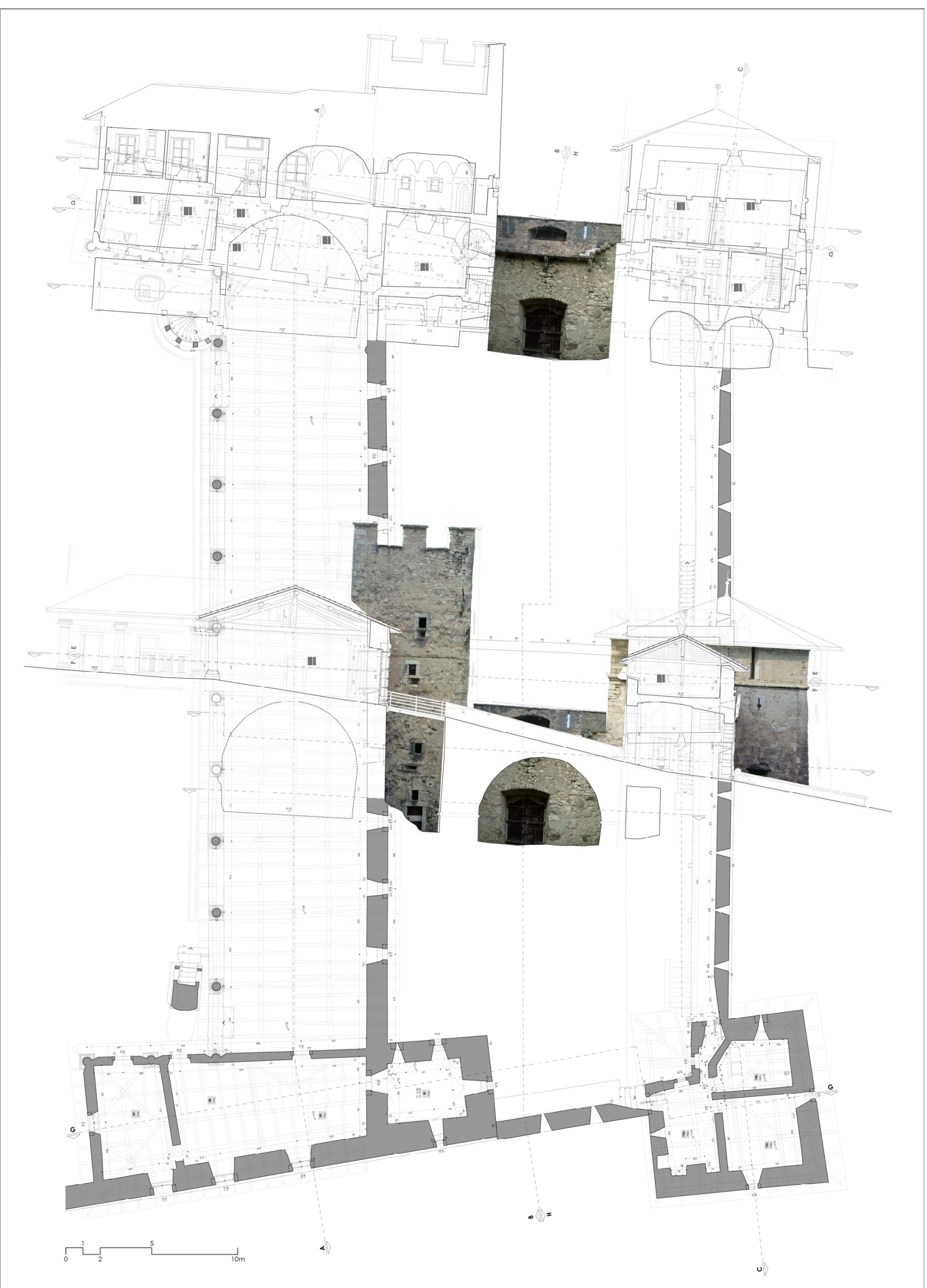

Figure 2. Thun Castle: geometrical surveys of external walls 


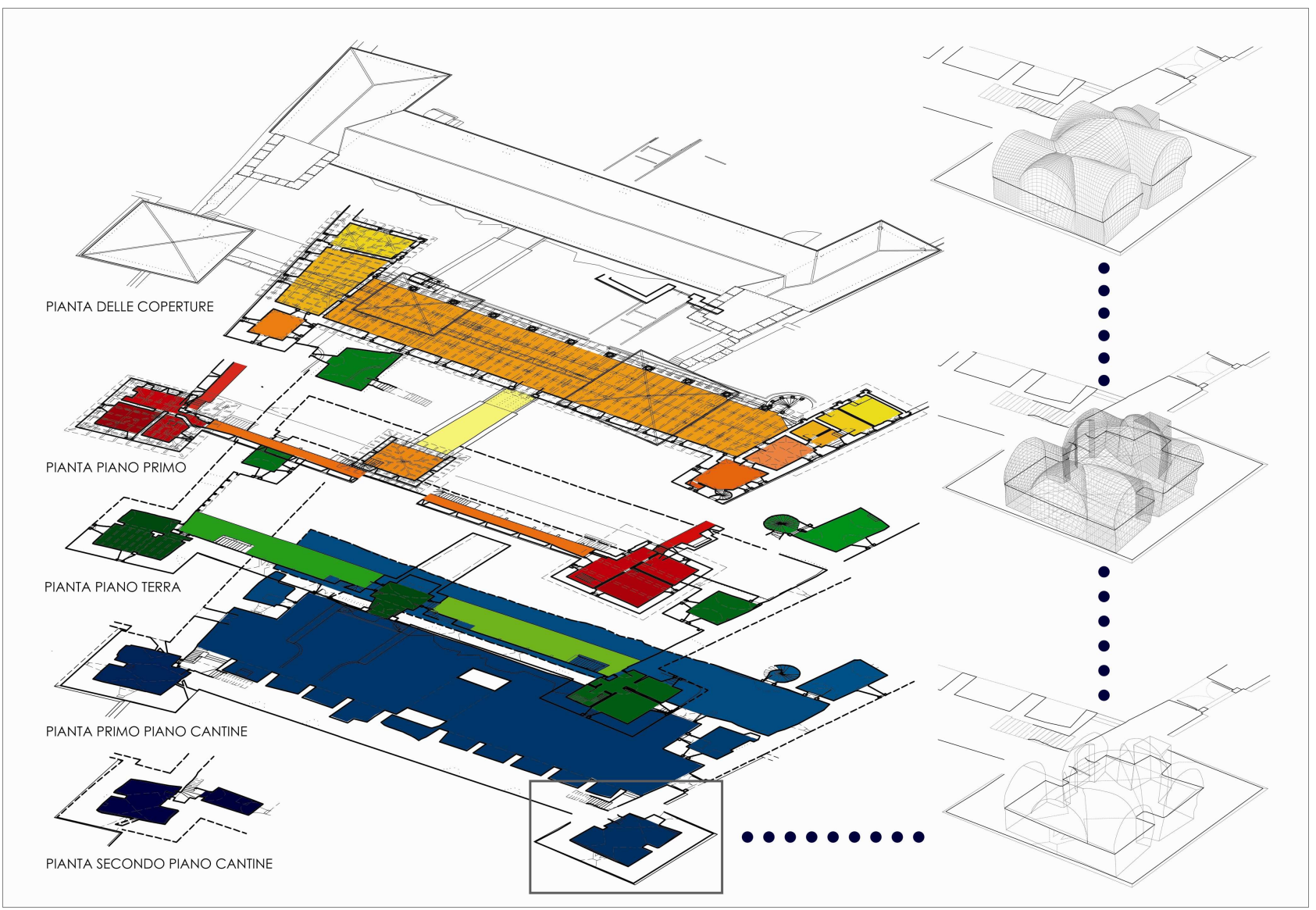

Figure 3. Layout of the interactive digital map for the virtual museum

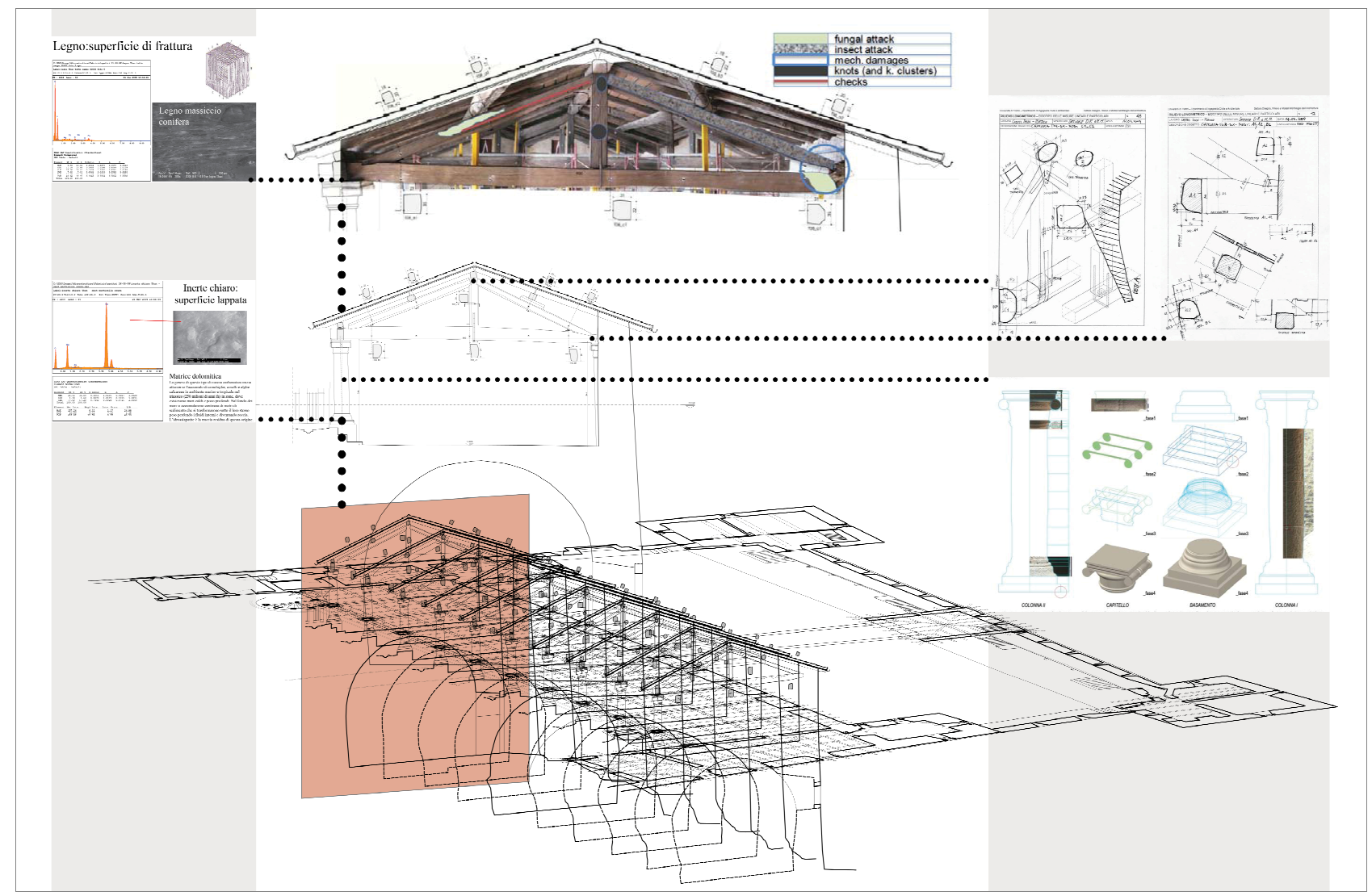

Figure 4. Layout of the data integrated management in the 3D digital model 


\section{MULTISCALAR MODELS AND HYPERTEXTS: A PROTOTYPE}

The destination of the castle to "historical habitation museum" offers the public the opportunity to benefit from a unique museum heritage both for the quality of the artistic-historical supply, including items related to everyday life, and the system of relations between fortified building and landscape. On this front the context of the Non Valley offers as many points of view as many thematic ideas for interpretation and divulgation: morphological, orographical and catchment aspects of areas of the territory; the old and new routes and the relative environmental changes on settlements and business activities; compact and diffuse settlements, that over time have been preserved or processed according to not always clear dynamics, the system of fortified and religious buildings; the network of sites which still attest to close relations with Thun family; the natural and artificial elements that emerge in landscape perception, both today both the one documented by iconography and historical maps.

At the scale of architecture in general and with reference to the interior of the Thun Castel in particular, the idea of a virtual museum that can be visited on-screen is an alternative way to describe and communicate the things that usually occupy exhibition rooms, traditionally only set up with illustrated panels; but the virtual museum is an important media addition to the real museum, characterized by a remote and from different reading levels access possibility, depending on the amount of information handled and the differing needs of the users.
If this idea of museum is projected beyond the size of the building and outside of its spaces, the architectural work is transformed from container to content and becomes part of a wider system of elements that characterize a whole territory; at a landscape scale the objectives of conservation and construction of a historical memory, which can be achieved maintaining a particular number of physical objects and using digital representation and hypertext systems, do not change.

The concept of museum expanded to land area is an instrument of cultural development for an entire living environment, since it allows to link the events and tracks today visible to the circumstances and sedimentary materials layers in time: the various components of the physical and anthropic landscape, sometimes survived as fragments, find a possible interpretation and a natural completion in the virtual dimension and the multimediatic story. Not only this: the objects that, in direct experience of physical places, are perceived as entities separated from by orographic conformation or difficult routes, have in a zenith view of the map a chance to be synthetically described and related, referring both to the spatial parameters and to time reading keys.

Hypertextual tecniques give an essential contribution to the realization of the informative system and to data recording, management and communication that are the base of a virtual museum. The pages of the hypertext contain both historical and archival documents and the results of the fieldwork: the link established between indirect sources and direct sources is one of the elements that characterizes the informative web-reachable system and it lets to achieve a closer events comprehension from the hypertext.

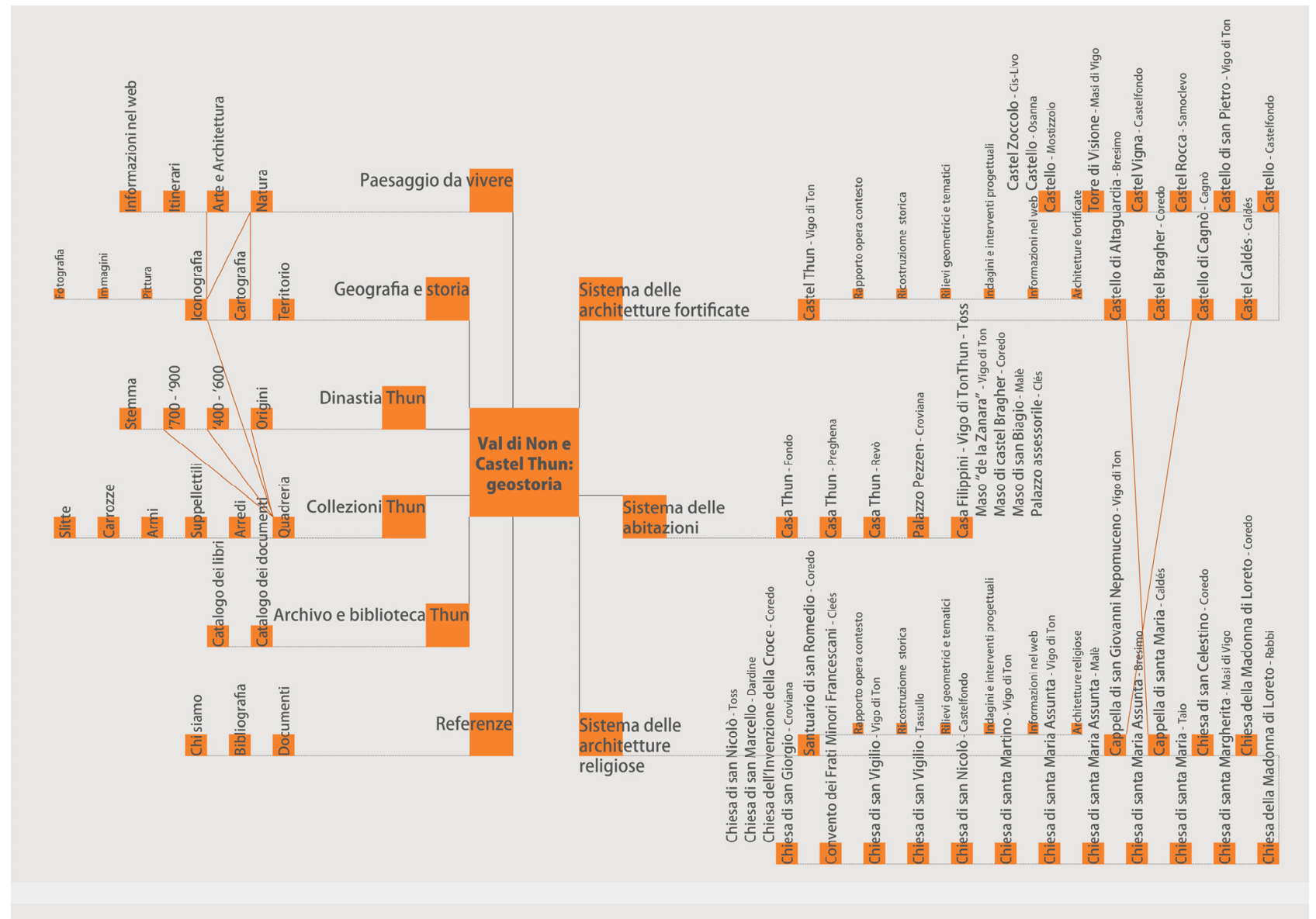

Figure 5. Conceptual map of the informative system "Val di Non e Castel Thun: geostoria" 
International Archives of the Photogrammetry, Remote Sensing and Spatial Information Sciences, Volume XXXVIII-5/W16, 2011 ISPRS Trento 2011 Workshop, 2-4 March 2011, Trento, Italy

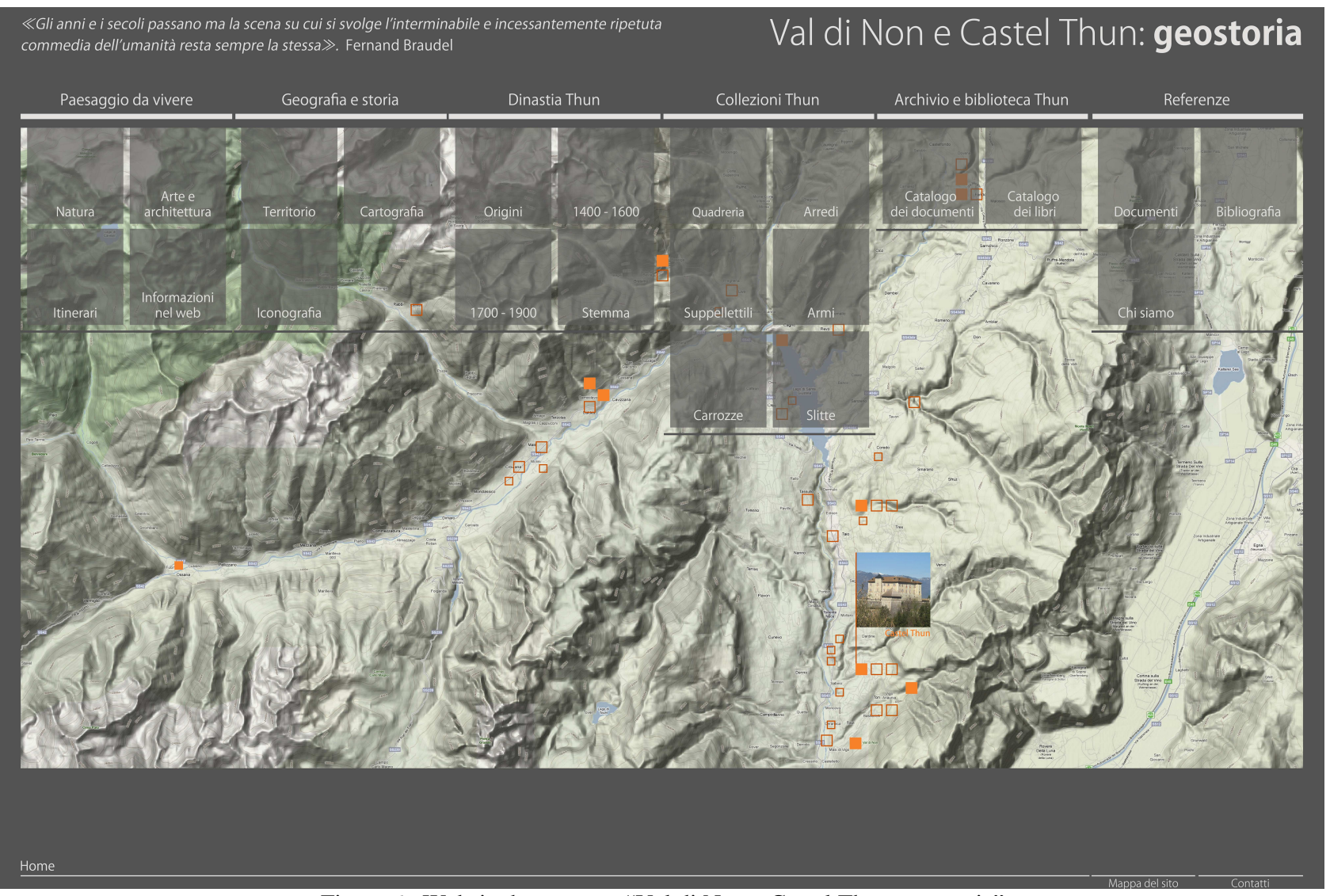

Figure 6. Website homepage: "Val di Non e Castel Thun: geostoria"

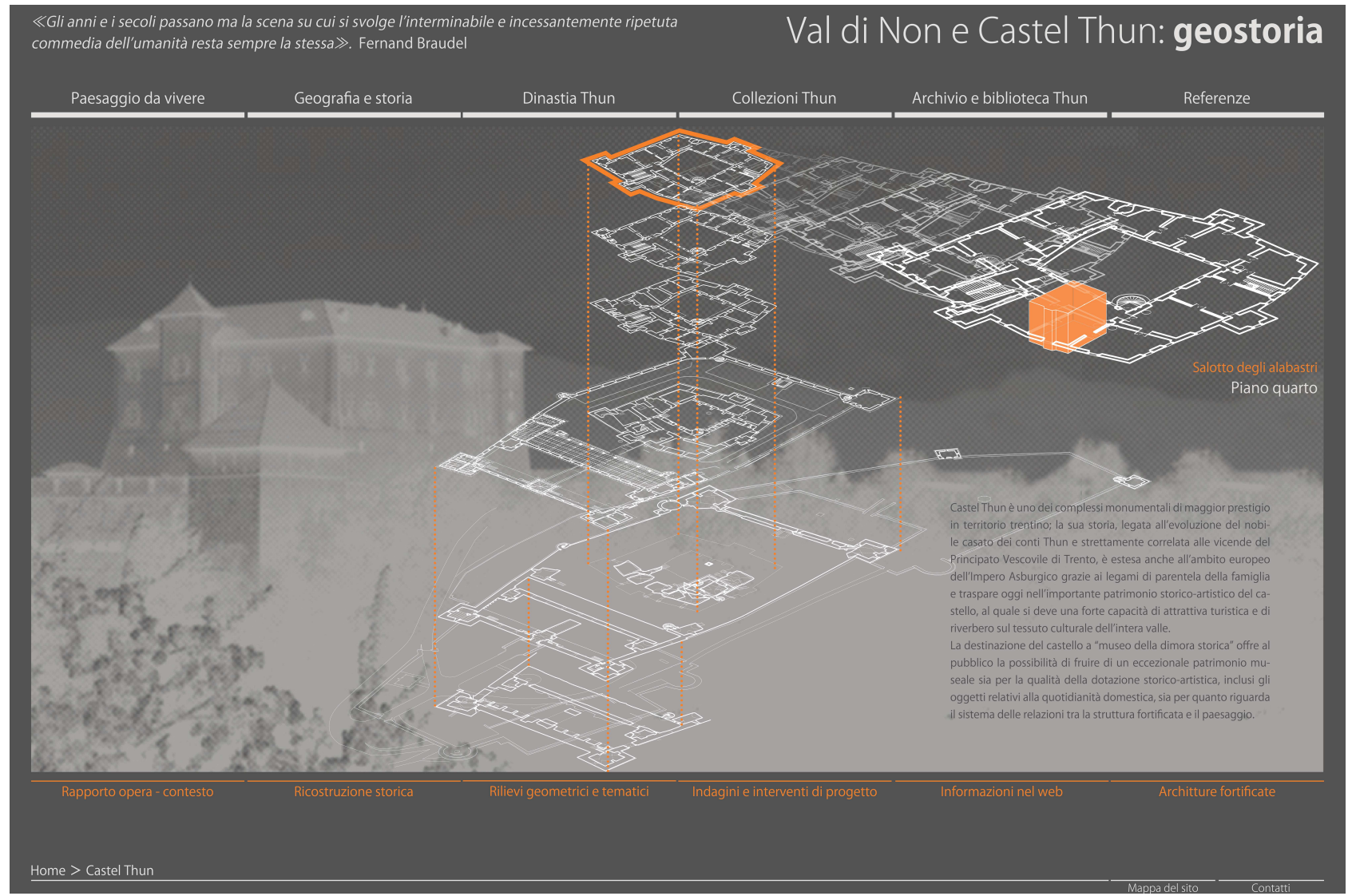

Figure 7. Consultation screen of information about Thun Castle 
The meaning of this fact-finding operation can be compared to the sense of ideal buildings models reconstruction but, while 3D representations of the stages of historical and constructive development conclude an interpretative path than hypertext reading produce synthesis always open to change because of changing of the use of virtual data/objects whole.

The experimental work of hyper-textual construction is based on the reorganization and cataloging of existing documentation, on drawing up general or punctual lists depending on the more or less relevant interest to the knowledge of the castle and the valley, on the provision in appropriate digital formats of all the available information; the latter phase, in particular ensures the widest possible manipulation of data and precise integration of texts, images and sounds that, translated into numerical language, can represent in combined ways the information traditionally associated with different media.

The manipulability is one of three major innovations introduced by hypertext systems in the communication process: firstly, it recognizes the change in size, shape and colour of data; secondly, the multimediality, allowing instead the intertwining of different codes of expression used in a dynamic and combined way; ultimately, the interactivity, that explicitly alters the information given in the communication process, depending on the choices made by users and that may cause the system to adapt the type of transmitted data to the demands of the recipient.

The hypertext prototype "Non Valley and Thun Castle: geohistory" is not just manipulatable, multi-mediatic and interactive, but it is also multi-scalar: at the various territorial, urban and architectural levels, it makes information available through two search options, one assigned to a graphics structure that allows the extraction of data from a map, and the other contained in a thematic structure organized by keyinterpretations.

The system interface is both didactic and evocative: it is planned so that everything is clear and explicit and each step transition is intelligible, but it also gives space to personal insight and to a gradual discovery of connective network. Whereabouts information are organized according a sequence of pages/screens linked to the landscape map that appears at the beginning: in this way it is possible to investigate each building of house system, fortified architecture system and religious architecture one; on the other side, the wholes of thematically grouped data like geographic and historical contest, famous people, artworks, archival documents and material culture objects become accessible by the corresponding button those show all workable researces.

\section{CONCLUSIONS}

The tools of communication have been and will always be factors in the transformation of thought, culture and society; today's digital technologies make obsolete traditional patterns of vertical transmission of information, in favour of circular or grid communication patterns which tend to counteract asymmetry of roles between sender and receiver. The construction of knowledge and structural instruments of information not only allow the containment, update and manipulation data of all kinds, but also guarantees a diversified availability depending on many levels of interest, is so made possible.

The experience described in these pages document how hypertext techniques address the non-sequential nature of knowledge; the original appearance of information systems and its graphic interface, is to use territory as an area of interaction between the user and the information, free movement field within the great amount of digital data. Hypertext offers the user a mapping, which refers to the contents of a physical reality but, simultaneously, offers itself as a container for a digital environment; the landscape so becomes the theme of multiple logical paths, while the map is the graphic index that leads to the discovery of the different levels of data by means of dynamic consultation gestures.

The "Non Valley and Thun Castle: geo-history" stems from an attempt to interpolate the ideas of virtual museum and digital library: the first intended as a set of informatics solutions that give the possibility of an increase in reality, the second viewed as the union of an electronic catalog and the online network. The physical environment has resulted in an interactive virtual environment that is, in equal measure, the exhibition of reality and the list of its resources.

The objective of the study is to link data, architecture and places spread out in the landscape, to then retrieve them according to a variety of strategies, but with the logic of the traveler who wants to establish a strong contact with the explored object and tries to understand all its implications.

The realized prototype shows that, like so many other examples available on the network, the relations that develop between us and multimedia communication systems, generate a strong link between cognitive and perceptual process: this means that through multimedia, dynamic approach to knowledge and the sensorial solicitation, educational processes and cultural systems in force in contemporary society can both be addressed; but to do this, telematic techniques of knowledge transmission must be used within a specific intellectual attitude, to achieve educational environments resulted from a genuine rapprochement between technological and aesthetic knowledge: the multi-media text, in fact, not only is a product of informational application but has the legitimacy of theoretical object.

\section{REFERENCES:}

Bettetini, G., Gasparini, B., Vittadini, N., 1999. Gli spazi dell'ipertesto. Bompiani, Piacenza.

Bianconi, F., 2005. Segni digitali. Sull'interpretazione e il significato della tecnologia digitale per la conservazione dei beni culturali. Morlacchi Editore, Perugia.

Botteri Ottavini, M., Dal Prà, L., Mich, E., 2007. Arte e Potere dinastico. Le raccolte di castel Thun dal XVI al XIX secolo. Provincia Autonoma di Trento, Trento.

Camerlengo, L., Chini, E., de Gramatica, F., 2010. Castel Thun. Skira, Milano.

Ceconello, M., Spallazzo, D., 2010. Virtual city, virtual landscape. Enhanced tool for design and planning. In: APEGA 2010. New lines of research in Building Engineering, Editorial Marfil, Alcoy, pp. 129-137.

Ferrari, S., 2010. I luoghi dei Thun nelle valli del Noce. Itinerari d'arte e di storia. Castello del Buonconsiglio, Trento.

Ippoliti, E., 2010. Mappe, modelli e tecnologie innovative per conoscere, valorizzare e condividere il patrimonio urbano. Indagini sperimentali di sistemi integrati sul Piceno. In: Sistemi informativi integrati per la tutela, la conservazione e la 
valorizzazione del patrimonio architettonico e urbano, Gangemi Editore, Roma, pp. 239-319.

Massari, G. A., Riggio, M., Gadotti, F., 2010. "Respecting the Diversity". The Timber Roof of the "Cannons Loggia" in the Thun Castle (Italy). In: SAHC 2010. $7^{\text {th }}$ International Conference on Structural Analysis of Historic Constructions, Trans Tech Publications, Switzerland, pp. 1107-1112.

\section{ACKNOWLEDGEMENTS}

The authors G. A. Massari (par. 1 e 4), F. Luce (par. 3) and C. Pellegatta (par. 2) wish to acknowledge the "Superintendence for Architectural Heritage P.A.T." (S. Flaim, M. Cunaccia, M. Favero, V. Barbacovi) and "Castle Museum of Buonconsiglio, Provincial Memorials and Collections of Trento". The authors are also grateful to Maria Cristina Bonora and Katia Svaldi for their contribution at all phases of architectural survey and geometric restitution of the spaces of the Thun Castle and the development of detailed digital models of the "Cannons Loggia". They also thank Federica Avanza and Lorenzo Mattei for their help during on-site survey. 